\title{
A STUDY ON USE OF FNAC FOR THE DIAGNOSIS OF LYMPHADENOPATHY IN HIV POSITIVE PATIENTS COMPARED TO CONVENTIONAL BIOPSY AND CORRELATION OF FINDINGS WITH CD4 COUNT
}

Pushpraj Singh Baghel ${ }^{1}$, Avinash Gupta ${ }^{2}$, Kamal Raj Singh ${ }^{3}$, Manish Agrawal ${ }^{4}$, Avdhesh Pratap Singh Kushwaha5, Ankana Thakur6, Vikash Jain7, Vishwa Deepak Tripath8

\section{HOW TO CITE THIS ARTICLE:}

Pushpraj Singh Baghel, Avinash Gupta, Kamal Raj Singh, Manish Agrawal, Avdhesh Pratap Singh Kushwaha, Ankana Thakur, Vikash Jain, Vishwa Deepak Tripath. "A study on use of FNAC for the diagnosis of lymphadenopathy in HIV positive patients compared to conventional biopsy and correlation of findings with CD4 count". Journal of Evolution of Medical and Dental Sciences 2013; Vol. 2, Issue 48, December 02; Page: 9261-9268.

BACKGROUND: Lymphadenopathy is a common clinical presentation in HIV/AIDS patients and conventional lymph node biopsy is the standard procedure for the diagnosis of this condition but the procedure incurs a high risk for healthcare providers. OBJECTIVES: The aim of this study was to analyze the cytological patterns of lymph node lesions in HIV/AIDS patients and to compare the results of Fine Needle Aspiration Cytology (FNAC) with conventional lymph node biopsy, along with the correlation of findings with CD4 count. MATERIALS AND METHODS: This study is a prospective comparison of an alternative procedure for the diagnosis of lymph node lesions in HIV/AIDS patients, Fine Needle Aspiration Cytology (FNAC), with the conventional method. The study population comprises 73 HIV/AIDS patients who attended the Department of medicine (ART centre), N.S.C.B Medical College Jabalpur. Aspirates were stained routinely with haematoxylin and eosin, Wrights and Ziehl-Neelsen stains. Special stains were done in selected cases. RESULTS: Cytological diagnosis included reactive (46. 6\%), tuberculous (31.5\%), non-specific chronic granulomatous (8.2\%), suppurative (9.5\%), Hodgkins lymphoma (1.4\%), Suspicious Non- Hodgkins lymphoma $\mathrm{n}(1.4 \%)$, Smear inadequate (1.4\%). Reactive and tuberculous lesions were further categorized. Each lesion was correlated with clinical details and CD4 counts. AFB grading was done on Ziehl-Neelsen stained smears in tuberculous lymphadenitis cases. CONCLUSION: Fine Needle Aspiration Cytology of lymph node is very useful for segregating lymphadenopathy cases in HIV/AIDS patient. FNAC is practical, convenient, safe, and relatively painless. Correlation of lesions with mean CD4 count and AFB grading reflects immunity, stage of disease and disease activity.

INTRODUCTION: The incidence of human immunodeficiency virus (HIV) infection is increasing in Asia particularly in the Indian subcontinent.[1] Regardless of portal of entry of HIV; lymphoid tissues are the major anatomic sites for establishment and propagation of HIV infection. [2] HIV infection is often associated with a number of opportunistic infections and malignancies, presenting with lymphadenopathy as one of the earliest manifestations of HIV infection. [3]Great advances have been made in the treatment of patients with HIV infection, so early diagnosis of opportunistic infection is of critical value in providing each patient with the best opportunity to live a long and healthy life despite the presence of HIV infection. [4]In developing countries like India with a huge population and socioeconomic constraints, there is a great need for a simple investigative technique for HIV infected lymphadenopathy cases. [1] The most useful diagnostic procedures for HIV patients with lymphadenopathy is lymph node biopsy (Gold standard), but the method has several drawbacks: - it is time consuming, can be harmful to healthcare providers being prone to work-related transmission 


\section{ORIGINAL ARTICLE}

of HIV infection and needs a lot of resources, elaborate health precautions must be observed in the operating theatre, and often the patients may be too ill for surgical intervention. [11]In order to cope with these problems, we demonstrate another method to make the diagnosis in HIV patients with lymphadenopathy, i.e. fine needle aspiration, which is safer and more convenient to perform and aspiration can be carried out in an outpatient setting or at the bedside.

KEY WORDS: Lymphadenopathy, FNAC, HIV, AIDS

MATERIALAND METHOD: The study was a hospital based prospective study, done from August 2009 to September 2010, carried out in the Department of pathology and Department of medicine (ART centre), N.S.C.B Medical College Jabalpur. In the present study, 73 HIV positive cases with lymphadenopathy who attended the ART centre were included. Patients who presented with only inguinal lymphadenopathy and/or lymphadenopathy of less than $0.5 \mathrm{~cm}$ in diameter were excluded from the study. With informed consent, lymph node aspirations were performed from 73 cases using 23- gauge needle and $10 \mathrm{ml}$ disposable syringe. We used non toothed forceps to immobilize the lymph node in place of hand to reduce the chances of needle stick injury (Singh's Method). Aspirates were deposited very closely to the surface of the labeled glass slides to prevent the creation of an aerosol, subsequently air dried, alcohol fixed and heat fixed smears were made. For each case of cytology and histology, haematoxylin and eosin, Wrights and Ziehl-Neelsen staining were routinely done. However special staining was done in selected cases. Acid-Fast Bacilli grading was done on Ziehl-Neelsen stained smears. CD4+ lymphocyte counts were correlated with various lymph node lesions. The relevant clinical data were obtained from the request forms or, where available, from the clinical notes. The cytological diagnoses of the FNA material were compared with the histological diagnoses from the surgically removed lymph nodes or with the clinical outcome in the cases where a biopsy specimen was not available.

Ethical Considerations: All data were treated confidentially, under the supervision of the ethical committee of the N.S.C.B. Medical College. All enrolled patients gave their informed consents regarding the procedure, its benefits, and all potential risks.

Data Analyses: All data were analyzed by descriptive statistics and chi-square comparison for laboratory results via SPSS.

RESULT: In our study majority of cases (69.8\%) were in 30-49 year age group, which is comparable to NACO guidelines[6], in which maximum number of cases are in sexually active age group of (30-49 years). Males were affected more (72.60\%) than females (27.40\%) with M: F ratio of 2.65:1. Majority of cases (45.20\%) were drivers and illiterates or with education upto primary level only (53.41\%). Majority of the cases (61.7 \%) had weight < $44 \mathrm{~kg}$. Maximum numbers of cases $76.71 \%$ were in WHO stage-III. The sites of the lymph node aspirates were, cervical in $75.34 \%$, axillary in $5.47 \%$,combined axillary \& cervical in $19.17 \%$. The size of lymph nodes varied from 0.5 to $3 \mathrm{~cm}$ in their largest diameter. Majority of cases (52.05\%) had lymphadenopathy since 5 months.

The cytological diagnoses of the 73 aspirated cases were: reactive changes, $n=34(46.6 \%)$; tuberculosis, $\mathrm{n}=23(31.5 \%)$; Chronic nonspecific granulomatous, $\mathrm{n}=6(8.2 \%)$; Suppurative, $\mathrm{n}=7$ (9.5\%); Hodgkins lymphoma, $\mathrm{n}=1$ (1.4\%); Suspicious Non- Hodgkins lymphoma $\mathrm{n}=1(1.4 \%)$; Smear inadequate $\mathrm{n}=1(1.4 \%)$. 
The diagnosis of reactive changes was based on finding a heterogeneous population of cells, which included a spectrum of small and large lymphocytes, fragments of reactive follicular centre cells, including tangible body macrophages, syncytia of dendritic reticulin cells, and some plasmacytoid cells were also seen. The cytological diagnosis of reactive changes also included the progressive generalised lymphadenopathy (PGL) seen in AIDS.

Mean age of the presentation of tuberculous lymphadenitis was $35 \pm 8$ years, and was seen predominantly in males with M: F ratio of 1.9:1. Most of the cases (78.26\%) of tuberculous lymphadenitis were in WHO stage III. The FNA material obtained from lymph nodes with tuberculous lymphadenitis showed caseation necrosis or epithelioid granulomata identical in appearance with those seen in HIV negative patients. The granulomata were composed of syncytial aggregates of oval or fusiform epithelioid histiocytes with "blunt ended" and sometimes bent or curved nuclei. Langhans' type giant cells were very occasionally seen.

Results of cytological study from FNAC compared to results of histological study from conventional biopsy: Forty three corresponding histological lymph node biopsy specimens were available for comparison; all biopsy specimens were adequate for pathological diagnosis. Out of 18 cases of reactive lymphadenitis 17 cases were according to the cytological findings in histology, in cases of tubercular lymphadenitis 15 out of 16 cases were according to the cytological findings, in cases of chronic non specific granulomatous lymphadenitis 2 cases out of 4 cases were non specific and 2 cases were tubercular so it was $50 \%$ for each case. In cases of suppurative lymphadenitis both cases were according to cytological findings. One case of Hodgkins lymphoma was confirmed on histology, one case of suspicious non- Hodgkins lymphoma and smear inadequate finding on cytology turned out to be reactive lymphadenitis on histology[Table -I].Thirty FNAC cases were subjected to clinical follow up alone and the findings were identical with the cytodiagnosis.

\begin{tabular}{|c|c|c|c|c|c|}
\hline \multirow{2}{*}{ Cytological finding } & \multicolumn{4}{|c|}{ Histological finding } & \multirow{2}{*}{ Total } \\
\hline & Reactive & Hodgkins lymphoma & Tuberculosis & Suppurative & \\
\hline Reactive lymphadenitis & $\begin{array}{c}17 \\
(94.1 \%)\end{array}$ & $\begin{array}{c}0 \\
(0.0 \%)\end{array}$ & $\begin{array}{c}1 \\
(5.9 \%)\end{array}$ & $\begin{array}{c}0 \\
(0.0 \%)\end{array}$ & $\begin{array}{c}18 \\
(100.0 \%)\end{array}$ \\
\hline $\begin{array}{l}\text { Tuberculous } \\
\text { lymphadenitis }\end{array}$ & $\begin{array}{c}1 \\
(6.2 \%)\end{array}$ & $\begin{array}{c}0 \\
(0.0 \%)\end{array}$ & $\begin{array}{c}15 \\
(93.8 \%)\end{array}$ & $\begin{array}{c}0 \\
(0.0 \%)\end{array}$ & $\begin{array}{c}16 \\
(100.0 \%)\end{array}$ \\
\hline $\begin{array}{l}\text { Chronic non specific } \\
\text { granulomatous }\end{array}$ & $\begin{array}{c}2 \\
(50.0 \%)\end{array}$ & $\begin{array}{c}0 \\
(0.0 \%)\end{array}$ & $\begin{array}{c}2 \\
(50.0 \%)\end{array}$ & $\begin{array}{c}0 \\
(0.0 \%)\end{array}$ & $\begin{array}{c}4 \\
(100.0 \%)\end{array}$ \\
\hline Suppurative lymphadenitis & $\begin{array}{c}0 \\
(0.0 \%) \\
\end{array}$ & $\begin{array}{c}0 \\
(0.0 \%) \\
\end{array}$ & $\begin{array}{c}0 \\
(0.0 \%) \\
\end{array}$ & $\begin{array}{c}2 \\
(100.0 \%) \\
\end{array}$ & $\begin{array}{c}2 \\
(100.0 \%) \\
\end{array}$ \\
\hline Hodgkins lymphoma & $\begin{array}{c}0 \\
(0.0 \%)\end{array}$ & $\begin{array}{c}1 \\
(0.0 \%)\end{array}$ & $\begin{array}{c}0 \\
(0.0 \%)\end{array}$ & $\begin{array}{c}0 \\
(0.0 \%)\end{array}$ & $\begin{array}{c}1 \\
(100.0 \%)\end{array}$ \\
\hline $\begin{array}{l}\text { Suspicious non- Hodgkins } \\
\text { lymphoma }\end{array}$ & $\begin{array}{c}1 \\
(100.0 \%)\end{array}$ & $\begin{array}{c}0 \\
(0.0 \%)\end{array}$ & $\begin{array}{c}0 \\
(0.0 \%) \\
\end{array}$ & $\begin{array}{c}0 \\
(0.0 \%)\end{array}$ & $\begin{array}{c}1 \\
(100.0 \%) \\
\end{array}$ \\
\hline Smear inadequate & $\begin{array}{c}1 \\
(100.0 \%)\end{array}$ & $\begin{array}{c}0 \\
(0.0 \%)\end{array}$ & $\begin{array}{c}0 \\
(0.0 \%)\end{array}$ & $\begin{array}{c}0 \\
(0.0 \%)\end{array}$ & $\begin{array}{c}1 \\
(100.0 \%) \\
\end{array}$ \\
\hline Total & 22 & 1 & 18 & 2 & 43 \\
\hline
\end{tabular}




\section{ORIGINAL ARTICLE}

Results of AFB staining from FNAB compared to conventional biopsy:- In all 73 cases of FNAC, Ziehl-Neelsen staining was done and out of 34 cases of chronic non specific lymphadenitis 32 cases were negative i.e. $97 \%$ cases were according to the cytological findings. In cases of tubercular lymphadenitis 22 out of 23 were positive for AFB so $95.65 \%$ cases were according to the cytological findings. In cases of chronic non specific granulomatous lymphadenitis 3 cases out of 6 cases were negative i.e. $50.0 \%$ cases were according to the cytological findings whereas 3 cases i.e. $50.0 \%$ were positive.

In all 43 cases of histology, Ziehl-Neelsen staining was done and out of 22 cases of chronic non specific lymphadenitis all cases i.e. $100 \%$ cases were AFB negative. In cases of tubercular lymphadenitis 18 out of 18 i.e. $100.0 \%$ were AFB positive.

Cytological Findings and CD4 count cross tabulation was done and in case of chronic non specific lymphadenitis $53 \%$ cases had CD4 count $>200$, which is significant with $\mathrm{P}$ value of $<0.05$. In cytological findings of chronic non specific granulomatous lymphadenitis $33.3 \%$ cases had CD 4 count between 100-200, and 66.7\% had CD4 count between 200-300. In cytological findings of tubercular lymphadenitis $91.3 \%$ cases had CD4 count $<200$, with P value of $<0.001$ which is highly significant. In cytological findings of suppurative lymphadenitis $66.6 \%$ cases had CD4 count $>200$, with $\mathrm{p}$ value of $<0.05$ which is significant.

DISCUSSION: The present study demonstrated the utility of lymph node cytology in the diagnosis and segregation of lymphadenopathy cases in HIV positive patients to aid clinical management. In our study maximum numbers of cases $(76.71 \%)$ were in WHO stage-III. Predominant cytological diagnosis in this study was reactive lymphadenitis constituting $46.60 \%$ of cases; similar observations were also seen in the study conducted in India (Chandigarh) by Saikia et al[1] (40\%), in North America (California) by Bottles et al[9] (50\%), in Europe by Reid et al[10](51\%) and MartinBates et al[11](41\%). Tuberculous lymphadenitis was the second common lesion constituting 31.50\% cases in this study. Studies conducted by Shenoy et al[8](50\%)in Mangalore, Saikia et al[1](32\%)in Chandigarh and Jayaram et al[3](53.84\%) in Malaysia also observed tuberculous lymphadenitis as a common lymph node lesion. However studies conducted in California by Bottles et al[9] (17\%) and in Europe by Reid et al [10](15\%) and Martin-Bates et al[11](22\%) demonstrated lower number of cases in comparison with present study.HIV related tuberculosis is becoming common in India, on the contrary, neoplastic diseases are seen in increased frequency in America and Europe. In the present study one case of Hodgkin's lymphoma (1.40 \%) was seen. 


\section{ORIGINAL ARTICLE}

\begin{tabular}{|c|c|c|c|c|c|c|c|c|}
\hline \multirow[b]{2}{*}{ Author } & \multirow[b]{2}{*}{$\begin{array}{c}\text { Total } \\
\text { no. } \\
\text { case }\end{array}$} & \multirow[b]{2}{*}{$\begin{array}{l}\text { Reactive } \\
\text { lymphaden } \\
\text { itis } \%\end{array}$} & \multirow{2}{*}{$\begin{array}{l}\text { Mycobacter } \\
\text { ial } \\
\text { lymphaden } \\
\text { itis \% }\end{array}$} & \multirow[b]{2}{*}{$\begin{array}{c}\text { Nonspecific } \\
\text { granulomat } \\
\text { ous \% }\end{array}$} & \multirow[b]{2}{*}{$\begin{array}{c}\text { Suppurati } \\
\text { ve } \%\end{array}$} & \multicolumn{2}{|c|}{ Malignant } & \multirow[b]{2}{*}{$\begin{array}{l}\text { Oth } \\
\text { er }\end{array}$} \\
\hline & & & & & & $\begin{array}{c}\text { Prima } \\
\text { ry \% }\end{array}$ & $\begin{array}{c}\text { Sec. } \\
\%\end{array}$ & \\
\hline $\begin{array}{l}\text { Shenoy et } \\
\text { al }\end{array}$ & 48 & 17 & 50 & & 2 & 10 & 2 & \\
\hline $\begin{array}{l}\text { Bottles et } \\
\text { al }\end{array}$ & 113 & 50 & 17 & & & 30 & $\begin{array}{c}14.2 \\
8\end{array}$ & \\
\hline $\begin{array}{l}\text { Martin et } \\
\text { al }\end{array}$ & 23 & 41 & 22 & & & 22 & & \\
\hline Reid et al & 52 & 51 & 15 & & & 11 & & \\
\hline $\begin{array}{l}\text { Jayaram et } \\
\text { al }\end{array}$ & 39 & 25.64 & 53.84 & 2.56 & & 2.56 & & \\
\hline Saikia et al & 25 & 40 & 32 & & & 4 & 4 & \\
\hline Guru et al & 231 & 46.32 & 41.55 & 7.3 & 1.29 & 1.73 & 1.29 & \\
\hline $\begin{array}{l}\text { Present } \\
\text { study }\end{array}$ & 73 & 46.60 & 31.50 & 8.20 & 9.5 & 1.40 & & 2.8 \\
\hline
\end{tabular}

In our study, out of 18 cases of reactive lymphadenitis 17 cases were according to the cytological findings in histology. In cases of tubercular lymphadenitis 15 out of 16 cases were according to the cytological findings. In cases of chronic non specific granulomatous lymphadenitis 2 cases out of 4 cases were non specific and 2 cases were tubercular so it was $50 \%$ for each case. It correlates with the study of Martin-Bates E, et al[11] where agreement was between the cytological and histological diagnoses in 14 of the 16 surgically biopsied cases. Only one case of lymphoma was reported in present study constituting 2.33\%. Studies conducted by Saikia et al [1] (4\%) and Shenoy et al ${ }^{[8]}(10 \%)$ in India and Jayaram et al[3](2.56\%) in Malaysia also reported lower number of lymphoma cases similar to present study. Studies conducted in North America by Bottles et al[9] (30\%) and in Europe by Reid et al[10](11\%) and Martin Bates et al [11](22\%) had higher incidence of lymphoma when compared to the present study [Table II].

Overall sensitivity of Fine needle aspiration cytology compared to histology was $90.5 \%$, and specificity was $95.2 \%$, positive predictive value of the test was 95 .

Most common finding in tubercular lymphadenitis was presence of caseating material and second common finding was combination of two features either epithelioid cells or mature lymphocytes and Langhans giant cells which is comparable to study by Guru et al[5].

\begin{tabular}{|c|l|c|}
\hline S. no. & \multicolumn{1}{|c|}{ FNAC finding } & No. of cases \\
\hline 1. & Caseating material & 12 \\
\hline 2. & Epithelioid cells & 3 \\
\hline 3. & Mature lymphocytes and Langhans' giant cells & 2 \\
\hline 4. & Combination of 2 or more findings out of the above & 6 \\
\hline Total & & 23 \\
\hline
\end{tabular}

Table 3: FNAC findings of 23 cases of Tubercular Lymphadenitis 


\section{ORIGINAL ARTICLE}

Grading of AFB was done based on AFB staining pattern proposed by Kumar et al[7].Grade 2+ is the predominant pattern with 16 cases $(66.67 \%)$ in the present study which is similar to study done by Guru et al[5](60.41\%). In contrast grade 1+ was predominant pattern observed by Kumar et al[7]. This difference in staining pattern in present study is probably because of compromised immunity of patients as the former study included lymph node aspirates from both non-HIV individuals and HIV positive individuals.

\begin{tabular}{|c|c|c|c|c|}
\hline \multirow{2}{*}{ AFB staining pattern } & \multicolumn{2}{|c|}{ Kumar et al } & \multicolumn{2}{c|}{ Present study } \\
\cline { 2 - 5 } & No of cases & $\%$ & No of cases & $\%$ \\
\hline Grade 1+ & 105 & 77.2 & 6 & 25 \\
\hline Grade 2+ & 4 & 2.9 & 16 & 66.67 \\
\hline Grade 3+ & 27 & 19.85 & 2 & 8.33 \\
\hline Total & 136 & 100 & 24 & 100 \\
\hline
\end{tabular}

Table 4: Comparison of AFB staining pattern

Grade $1+=$ AFB was found after a careful search.

Grade $2+=$ AFB were singly scattered.

Grade $3+=$ AFB were found in large numbers arranged in faggots and singly, bacilli could be detected even under 10x.

Using tissue pathological diagnosis as the "Gold Standard", the AFB staining results collected from both procedures, FNAC and conventional lymph node biopsy, showed the same sensitivity and specificity in diagnosing HIV patients with lymphadenopathy ( $\mathrm{P}$ value $<0.05$ ), so when AFB staining was combined with the cytological results from FNAC, the sensitivity and specificity increased to $100 \%$.

Considering the above fact we suggest that cytological analysis from FNAC along with the positive results of AFB staining are reliable for the diagnosis of mycobacterial infection, due to high positive predictive value of the procedure thus avoiding the conventional biopsy.

In our study maximum number of cases $(60.26 \%)$ had CD4 count $<200$ (P value $<0.05$ ) and shows that HIV associated lymphadenopathy, most commonly occur with low CD4 count.

In this study, most of the cases of reactive lymphadenitis (53\%) had CD4 count highest among all the other lesions (CD4 count > 200) which is significant ( $\mathrm{P}$ value <0.05); Grossl et al[12] had recorded a mean value of 237 in reactive lesions in their study. In cases of tubercular lymphadenitis $(91.3 \%$ ) cases had CD4 count $<200$, (P value $<0.001$ ) which is highly significant. In cases of suppurative lymphadenitis (66.6\%) cases had CD4 count $>200$, ( $p$ value $<0.05$ ) which is significant. Another finding is that as the WHO stage of patient increases CD4 count decreases accordingly.

CONCLUSIONS: Fine Needle Aspiration Cytology is a valuable tool for identification of opportunistic infections, neoplastic lesions and non-neoplastic lesions. Correlation of lesions with CD4counts provides information about immune status and stage of the disease. In addition, AFB staining along with cytological study increases the sensitivity and specificity of the procedure. We recommend that Fine Needle Aspiration Cytology should be the first diagnostic procedure in clinics for the diagnosis of the cause of lymphadenopathy in HIV/AIDS patient, because it is practical, convenient, safe, and 


\section{ORIGINAL ARTICLE}

relatively painless, does not require hospitalization or anesthesia does not leave a scar and gives a rapid result for initial diagnosis than conventional biopsy.

\section{REFERENCES:}

1. Saikia UN, Dev P, Jindal B, Saikia B: Fine needle aspiration cytology in lymphadenopathy of HIVPositive cases. ActaCytol. 2001; 45: 589- 592.

2. Beck J.M, Rosen MJ et al; Pulmonary complication of HIV, AM. J. Respi Critical care Medicine Vol. 164: 2126-2129.

3. Jayaram G, Chew MT: Fine needle aspiration cytology of Lymph nodes in HIV- infected individuals. ActaCytol. 2000; 44: 960-966.

4. Fauci AS, Lane HC: Human immunodeficiency virus disease: AIDS and related disorders. In: Harrison's Principles of internal medicine. 16th ed. Kasper DC, Fauci AS, Longo DL, Braunwald E, Hauser SL, Jameson IT, editors. United States of America, Mcgraw - Hill companies, 2005, p. 1076-1039.

5. Guru Kumar, Kulkarni MH, Kamakeri NS: FNAC of peripheral lymph node in HIV positive patients scientific medicine 2009;1:2

6. Training module of National AIDS control organization (Adapted from web. www. Nacoonline. Org.)

7. Kumar S, Ferns S, Sujatha S, Jatiya L: Acid - fast staining patterns and their correlation with HIV positivity (lett). Actacytol. 2005; 49: 111- 112.

8. Shenoy R, Kapadi SN, Pai KP, Kini H, Mallya S, Khadilkar UN, et al: Fine needle aspiration diagnosis in HIV-related Lymphadenopathy in Mangalore, India. ActaCytol. 2002; 46: 35-39.

9. Bottles K, McPhaul LW, Volberding P: Fine- needle aspiration biopsy of patients with acquired immunodeficiency syndrome (AIDS): experience in an outpatient clinic. Ann Int Med. 1988; 108: 42-45.

10. Reid AJC, Miller RF, Kocjan GL: Diagnostic utility of fine needle aspiration(FNA) cytology in HIVinfected patients with lymphadenopathy. Cytopathology. 1998; 9: 230-239.

11. Martin-Bates E, Tanner A, Suvarna SK, Glazer G, Coleman DV: Use of fine needle aspiration cytology for investigating lymphadenopathy in HIV positive patients. J clinPathol. 1993; 46: 564-566.

12. Grossl NA, Mosunjac MI, Wallace TM: Utility of fine needle aspiration in HIV-position patients with corresponding CD4 counts. Four years experience in a large inner city Hospital. Actacytol. 1997; 41: 811- 816. 


\section{ORIGINAL ARTICLE}

\section{AUTHORS:}

1. Pushpraj Singh Baghel

2. Avinash Gupta

3. Kamal Raj Singh

4. Manish Agrawal

5. Avdhesh Pratap Singh Kushwaha

6. Ankana Thakur

7. Vikash Jain

8. Vishwa Deepak Tripath

\section{PARTICULARS OF CONTRIBUTORS:}

1. Assistant Professor, Department of Pathology, NSCB Medical College, Jabalpur.

2. Senior Resident, Department of Pathology, NSCB Medical College Jabalpur.

3. Senior Resident, Department of Anaesthesia, G.R. Medical College, Gwalior.

4. Assistant Professor, Department of Pathology, RD Gardi Medical College, Ujjain.

5. Assistant Professor, Department of Radiology, NSCB Medical College Jabalpur.
6. Senior Resident, Department of Pathology, NSCB Medical College Jabalpur.

7. Senior Resident, Department of Pathology, NSCB Medical College Jabalpur.

8. Senior Resident, Department of Medicine, NSCB Medical College, Jabalpur.

\section{NAME ADDRESS EMAIL ID OF THE CORRESPONDING AUTHOR:}

Dr. Pushpraj Singh Baghel,

F-44, Doctors Colony, NSCB Medical College, Garha, Jabalpur (M.P.).

Email - drpushprajsingh@gmail.com

Date of Submission: 12/11/2013.

Date of Peer Review: 13/11/2013.

Date of Acceptance: 19/11/2013.

Date of Publishing: 26/11/2013. 